\title{
INTERACTION BETWEEN ERYTHROMYCIN AND LINCOMYCIN IN STREPTOCOCCUS PYOGENES
}

\author{
D. I. ANNEAR \\ Department of Microbiology, Royal Perth Hospital, Perth, Western Australia
}

\section{Plates XV and XVI}

THE induction of lincomycin resistance by erythromycin in strains of Staphylococcus aureus that show dissociated resistance to erythromycin has been well documented and reviewed (Garrod, 1957; Griffith et al., 1965; Garrod, Lambert and O'Grady, 1973). In agardiffusion tests of this phenomenon the results indicate antagonism between the drugs (Griffith et al., 1965). Similar findings with Streptococcus pyogenes are reported here for the first time together with the observation of apparent synergy between the two drugs in one isolate of this species.

Dixon and Lipinski (1972) described several patterns of lincomycin and erythromycin resistance in Str. pyogenes including a paradoxical relationship between the concentration of lincomycin and its inhibitory effect. This relationship has been confirmed with some of the strains examined here and has been related to drug interaction.

The organisms with these unusual responses to erythromycin and lincomycin were compared with conventional strains that showed unequivocal sensitivity to both antibiotics.

Sensitivity patterns to the individual drugs were studied with agar-dilution methods and interaction studies were made with agar-diffusion methods.

\section{MATERIALS AND METHODS}

Organisms. All strains of Str. pyogenes were routine clinical isolates. They were sensitive to weak bacitracin and gave group A reactions by the precipitin method (Rantz and Randall, 1955) and the co-agglutination method ("Phadebact", Pharmacia). Strain QA was representative of organisms sensitive to both erythromycin and lincomycin; strain QB was an isolate representative of 10 strains that showed apparent antagonism between the two drugs; strain QC showed apparent synergy between the two drugs.

Media. The solid medium used was Columbia Agar Base (Oxoid) with $1 \%(\mathrm{w} / \mathrm{v})$ yeast extract and $6 \%(\mathrm{v} / \mathrm{v})$ citrated horse blood. Antibiotic plates and disks were made by conventional procedures.

Inocula. Glucose broth cultures, incubated for $16 \mathrm{~h}$ at $37^{\circ} \mathrm{C}$, were used as the source of inocula. For the disk tests, plates were flooded with a 1 in 100 dilution of these cultures and for the agar-dilution tests single-drop inocula of a 1 in 10 dilution were used. Agar-dilution tests were incubated for $48 \mathrm{~h}$ at $37^{\circ} \mathrm{C}$.

\section{RESULTS}

The results of the agar-dilution studies are shown in table I. Those for strain QA were as expected for a sensitive strain of Str. pyogenes. Strain QB showed a low but definite resistance to erythromycin and a high but paradoxical resistance to lincomycin. Strain QC also had a low level of resistance to erythromycin but was sensitive to lincomycin. The growth in the higher concentrations of lincomycin for strain QB was delayed and the colonies took $48 \mathrm{~h}$ to develop.

Fig. 1 shows the three types of drug interaction with each of the organisms after overnight

Received 7 Jan. 1977; revised version accepted 26 Sept. 1977.

J. MED. MICROBIOL.-VOL. 11 (1978) 


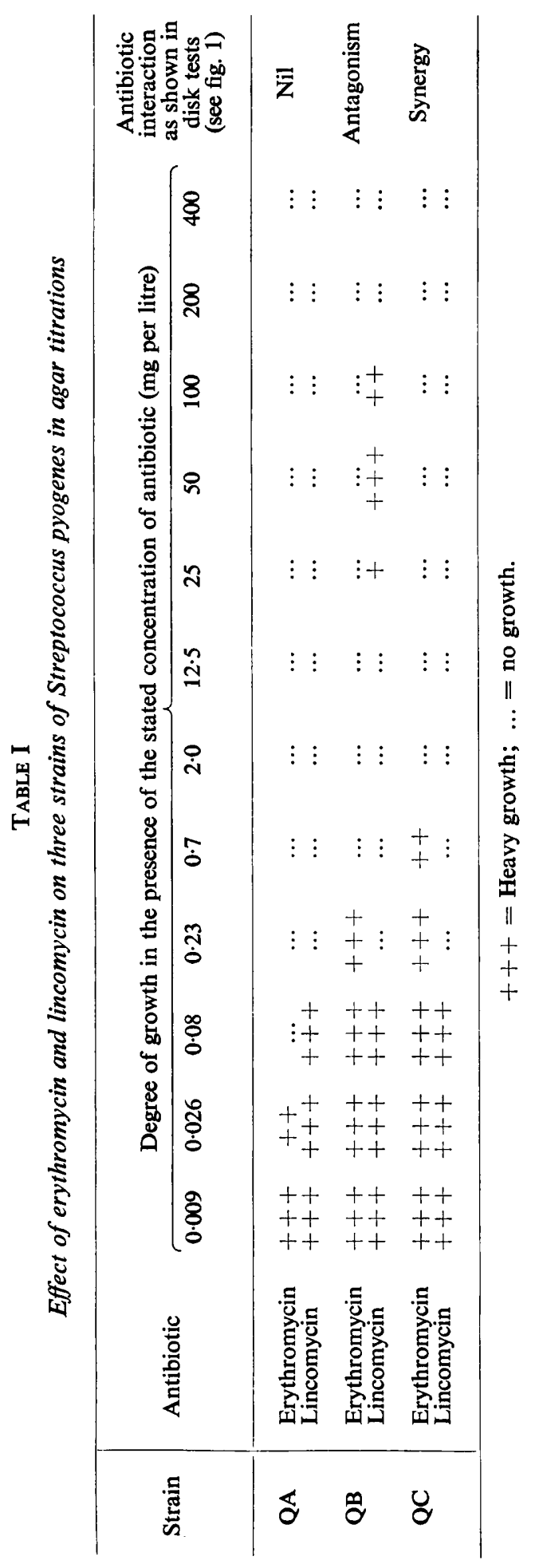


incubation. Antagonism and synergy for strains QB and QC respectively were clearly evident. After incubation for a further day the appearance of the zones for the control strain QA and for strain QC remained unchanged whereas with strain QB there was a progressive antagonism of lincomycin (fig. 2) until finally the entire zone was clouded with growth. It must be noted that the darker areas in the illustrations are those showing inhibition of growth and non-haemolysed blood whereas the pale speckled areas are those of dense growth and haemolysed blood.

The paradoxical zone of lincomycin activity for strain QB was also demonstrated by the agar-diffusion technique (fig. 3) and results paralleled those for the agar-dilution method. More specifically, the various zones from the disk outwards were: (1) a zone of growth inhibition without haemolysis, (2) a zone with colonies and haemolysis, (3) a wide zone of inhibition without haemolysis in its inner aspect but with haemolysis towards the perimeter, and (4) a zone of uninhibited growth with haemolysis. The results varied widely with the density of the inoculum and with incubation conditions. Thus, storage of inoculated plates at $4^{\circ} \mathrm{C}$ for several hours before incubation at $37^{\circ} \mathrm{C}$ gave a clearer demonstration of the paradoxical effect than incubation at $37^{\circ} \mathrm{C}$ alone. As with the agar-dilution method, the colonies in the zone of high lincomycin concentration did not develop until the 2nd day of incubation. It was apparent from a comparison of the density of growth in this zone with that in the outer areas of the plate that the organisms that grew in the former zone represented only a small proportion of the inoculum.

\section{Discussion}

There is sound evidence that the apparent antagonism of lincomycin against erythromycin in certain strains of Staph. aureus is due to a dissociated type of erythromycin resistance that induces resistance to lincomycin and that therefore can only be detected where the two drugs are present together. In the similar phenomenon described here with Str. pyogenes it is reasonable to assume that a similar mechanism is operating. However, the finding of a strain that shows synergy between the two drugs provides further data for consideration in connection with this problem.

Although the present studies do not provide quantitative data they do confirm previous observations (Dixon and Lipinski, 1972) concerning paradoxical zones of lincomycin activity for certain strains of Str. pyogenes that display a low level of resistance to erythromycin. The five categories of Str. pyogenes described by Dixon and Lipinski (1972) and in this paper are summarised in table II. Interactions were not recorded in the former studies but it is likely that testing would have shown them to be associated with categories 2 and 3 (table II). It is not possible with these limited data to show any firm correlations with the present study. However, strains with erythromycin resistance of the low level type may consistently show one or other interaction between that drug and lincomycin. It may also be of signifi-

TABLE II

Streptococcus pyogenes categorised according to features associated with responses to erythromycin and lincomycin

\begin{tabular}{|c|c|c|c|c|c|}
\hline Reference & $\begin{array}{c}\text { Category } \\
\text { (and number } \\
\text { of } \\
\text { strains) }\end{array}$ & $\begin{array}{c}\text { Response } \\
\text { to } \\
\text { erythromycin }\end{array}$ & $\begin{array}{c}\text { Response } \\
\text { to } \\
\text { lincomycin }\end{array}$ & $\begin{array}{l}\text { Paradoxical } \\
\text { zone with } \\
\text { lincomycin }\end{array}$ & $\begin{array}{l}\text { Interaction } \\
\text { between } \\
\text { erythromycin } \\
\text { and lincomycin }\end{array}$ \\
\hline $\begin{array}{l}\text { Dixon and } \\
\text { Lipinski (1972) }\end{array}$ & $\begin{array}{l}1 \\
2(4) \\
3 \text { ( }(2)\end{array}$ & $\begin{array}{l}\text { High resistance } \\
\text { Low resistance } \\
\text { Low resistance }\end{array}$ & $\begin{array}{l}\text { High resistance } \\
\text { High resistance } \\
\text { High resistance }\end{array}$ & \pm & $\begin{array}{l}\text { Not tested } \\
\text { Not tested } \\
\text { Not tested }\end{array}$ \\
\hline $\begin{array}{l}\text { Annear } \\
\text { (this paper) }\end{array}$ & $\begin{array}{l}4(8) \\
5(1)\end{array}$ & $\begin{array}{l}\text { Low resistance } \\
\text { Low resistance }\end{array}$ & $\begin{array}{l}\text { High resistance } \\
\text { Sensitive }\end{array}$ & $\underline{+}$ & $\begin{array}{l}\text { Antagonism } \\
\text { Synergy }\end{array}$ \\
\hline
\end{tabular}


cance that the strain (QC) that showed synergy between the two drugs did not display a paradoxical response to lincomycin.

It would seem that strains of Str. pyogenes showing resistance to erythromycin or lincomycin or both should be investigated more fully. Those with moderate resistance to erythromycin may easily be missed in conventional disk testing unless care is exercised because the inhibition zones may be large. In checking such results the juxtaposition of lincomycin and erythromycin disks is of considerable value in revealing interactions. In this laboratory, strains of Str.pyogenes resistant to these drugs have not been common and the 10 isolates described here were collected over several years. No strains of categories 1 or 3 (table II) have been isolated so far.

\section{SUMMARY}

Ten strains of Streptococcus pyogenes isolated were moderately resistant to erythromycin and highly but paradoxically resistant to lincomycin, and they showed antagonism between the two antibiotics. Another strain was moderately resistant to erythromycin and sensitive to lincomycin, and it showed synergism between the two antibiotics.

I wish to thank Mr C. Richardson, Princess Margaret Hospital, Perth, for supplying Streptococcus pyogenes strain QC, and Mr C. J. Barry of the Medical Illustrations Department, Royal Perth Hospital, for the photographs.

\section{REFERENCES}

Dixon, J. M. S. AND LIPINSKI, A. E. 1972. Resistance of Group A $\beta$-hemolytic streptococci to lincomycin and erythromycin. Antimicrob. Agents Chemother., 1, 333.

GARROD, L. P. 1957. The erythromycin group of antibiotics. Br. med. J., 2, 58.

Garrod, L. P., Lambert, H. P. AND O'Grady, F. 1973. Antibiotics and chemotherapy, 4th ed., London.

Griffith, L. J., Ostrander, W. E., Mullins, C. G. And Beswick, D. E. 1965 . Drug antagonism between lincomycin and erythromycin. Science, N.Y., 147, 746.

RANTZ, L. A. AND RANDALL, E. 1955. Use of autoclaved extracts of hemolytic streptococci for serological grouping. Stanford med. Bull., 13, 290. 
DISSOCIATED RESISTANCE IN STR. PYOGENES

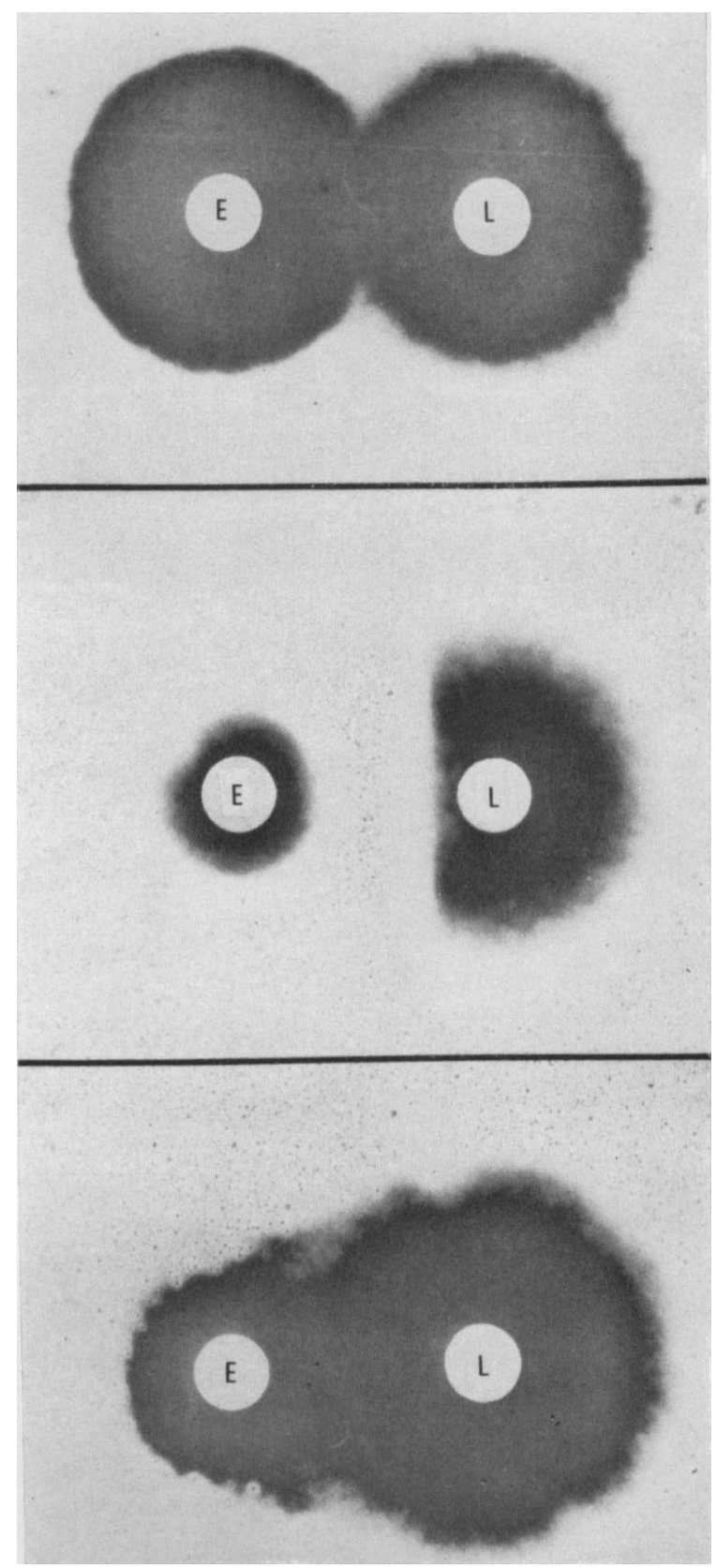

FIG. 1.-Interactions between erythromycin and lincomycin for strains QA (top), QB (centre) $\mathrm{QC}$ (bottom). $\mathrm{E}=$ erythromycin disk $(15 \mu \mathrm{g})$ and $\mathrm{L}=$ lincomycin disk $(15 \mu \mathrm{g})$. Plates incubated for $18 \mathrm{~h}$ at $37^{\circ} \mathrm{C}$. 
DiSSOCIATED RESISTANCE IN STR. PYOGENES
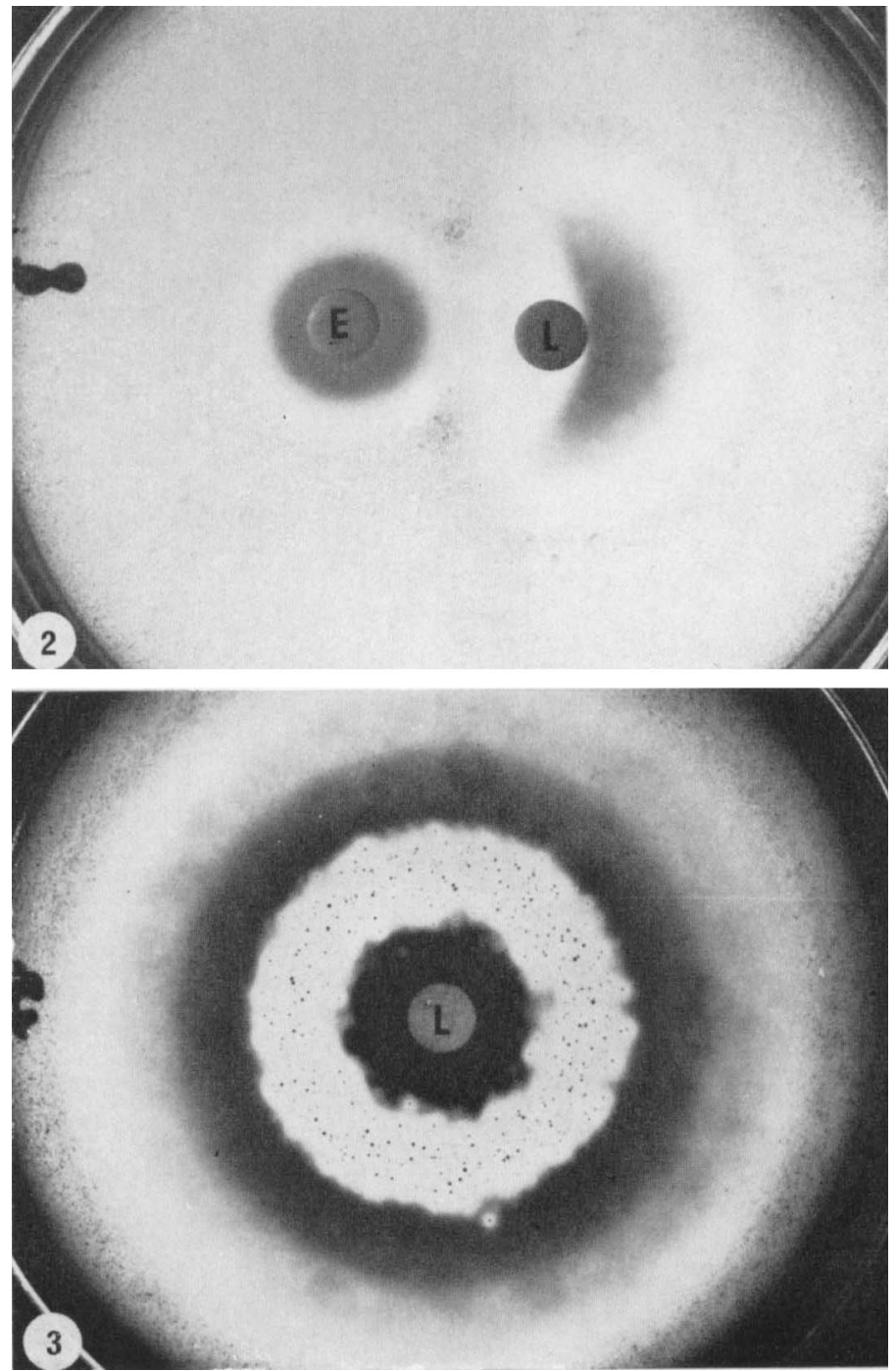

FIG. 2.-As for fig. I (centre) but after incubation for 2 days.

FIG. 3.-Paradoxical response of strain QB to lincomycin. Disk contains lincomycin $100 \mu \mathrm{g}$. Plate held at $4^{\circ} \mathrm{C}$ for $3 \mathrm{~h}$ then incubated at $37^{\circ} \mathrm{C}$ for $48 \mathrm{~h}$. 